\title{
An experimental approach to understanding banner adverts' effectiveness
}

Received (in revised form): 26th September, 2002

\section{Sung-Joon Yoon}

is Associate Professor of Marketing in the School of Business Administration at Kyonggi University, Seoul, Korea. His main research areas are in online advertising/marketing, consumer behaviour and marketing strategy.

\begin{abstract}
The primary objectives of this study were, using empirical data from Internet users in Korea, to discover the major motives for consumers' use of Internet (banner) adverts, and to determine the sources of effectiveness of banner adverts in terms of advert type (text vs picture) and advert content (information vs prize) by incorporating the theoretical premises developed on the role of the consumer's level of involvement on advert effectiveness.

The result showed that respondents wanted to use banner adverts for 'maintaining social relationships', 'rest and pass time,' 'curiosity,' 'practical reasons,' 'two-way communication,' and for 'interest in product'. Another result showed that image was significantly more effective than text for an Internet banner advert. It was also found that the level of advert involvement had a significant impact on the effectiveness of banner adverts, showing higher advert preference for advert type and advert content when consumers were highly involved. Consumers who were highly involved and those who had low involvement were both more positively responsive to image-based adverts than text-based adverts. Highly-involved consumers, however, were more positively responsive to prize adverts than to information adverts whereas low-involvement consumers were slightly more positively responsive to information adverts.
\end{abstract}

Sung-Joon Yoon PhD Associate Professor of Marketing,

Department of Business

Administration,

Kyonggi University

Seodaemoon-gu,

Choongjongro 2-ga, 71,

Seoul, Korea 120-702.

Tel: +82 2390 5135;

Fax: +82 2390 5135;

e-mail:

sjyoon@kyonggi.ac.kr

\section{INTRODUCTION}

A critical area of Internet research which requires keen attention is developing a theoretical framework which can explain and determine the cause and effects of successful banner adverts. Most extant studies attempted to explain the effectiveness of banner adverts in result-oriented terms such as conversion efficiency and promotional effectiveness. ${ }^{1,2}$ Hardly any, however, sought to understand the role of the consumer's perception of what is presented in a banner advert in connection with advert effectiveness. Therefore, a more holistic approach needs to be taken to measure the banner advert's effectiveness which not only takes into account consumers' information-processing mechanisms but provides a theoretical basis for understanding behavioural measures associated with adverts' effectiveness. ${ }^{3-5}$

Some researchers have attempted to explain the effectiveness of advertising from a rather narrower information processing paradigm. For instance, many cognitive psychologists have investigated 
the effects of human senses in the process of information storage. They tried to explain the differential effects of text and image on memory enhancement. ${ }^{6-9}$ They concluded that information conveyed by image is more easily recalled and recognised than textual information. But, due to the relative recency of banner advertising, a comprehensive approach to measuring the advertising effectiveness of the Internet has been sparse. Especially wanting are studies on measuring the effectiveness of banner adverts using more diverse sets of stimuli. Thus, more attention needs to be paid to understanding the effects of not only message type but also other characteristics of banner adverts. For instance, the advert message's intended objective may affect advert effectiveness through users' varying levels of comprehension or personal involvement. Also, other stimuli worth investigating are advert design, colour and size.

These research issues are addressed in this study in terms of the following two research objectives:

- dicovery of user-based motives for the use of banner adverts

- determination of the basis of the effectiveness of banner adverts. Specifically, the role of advert type (text vs image), advert content (information vs prize) and level of consumer involvement on advert effectiveness are investigated empirically.

\section{WHY DO CONSUMERS USE BANNER ADVERTS?}

Since the Internet is widely accepted as a new medium breaking the traditional boundaries of media advertising, any attempt to distinguish it from traditional media should include a broader base for understanding media audiences' needs and preferences. It was previously argued by researchers that cognitive 'matching' is necessary between system properties (ie being visual or verbal) and consumer preferential needs (ie preferring visual or verbal presentation) in order to ensure maximum user satisfaction. ${ }^{10}$

Until now, very few studies looked into the motives for using banner adverts. For example, Clawson ${ }^{11}$ found that consumers looked for control, convenience and customisation in their use of banner adverts. His finding suggests that advert consumers are intent on turning their conventional role as information receiver into that of information processor who is capable of choosing the kind of advert of interest to them. This finding on the importance of information seeking in the use of the Internet was later supported by Park et al. ${ }^{12}$ who approached the Internet usage motive from information on search behaviour. They argued that consumers primarily search for information on the Internet for the following three reasons:

- to satiate desire or curiosity relating to knowledge about a product or service - to get rid of boredom or monotony

- to achieve a positive goal despite the risk of uncertainty.

Also, Lee ${ }^{13}$ identified the following four major characteristics of banner adverts:

— intentional advert exposure

- information oriented advert

- global marketing

— high potential advert effectiveness.

Similarly, highlighting the informational aspect of banner adverts, another study found that the majority of respondents in its study (40.6 per cent) clicked on banner adverts with the intention of obtaining information. ${ }^{14}$ In addition, 28.6 
per cent of respondents said they clicked because they wanted discount coupons, prizes or free software, and 19.9 per cent reported that their reason for clicking related to the shape and graphics of banner adverts. This finding is significant in that, besides the importance of information sought by banner advert users, promotional elements like prizes also play a role in increasing the effectiveness of the adverts.

\section{THEORETICAL BACKGROUNDS AND HYPOTHESES}

Despite the importance of understanding relevant theoretical foundations, very few social science theories were actually adopted in explaining the motives for using adverts on the Internet. Hunter ${ }^{15}$ raised the possibility of using expectancy-value theory to understand what motivates a person to choose one medium over another. He quotes Dervin $^{16}$ in explaining the theory's applicability, postulating that 'exposure to mass communication results from persons' seeking valued consequences that they associate with particular messages or media'.

Other theories were pointed out as potentially useful for explaining the use of the Web. Most notably, researchers suggested the uses and gratifications theory to understand behaviour on the Web. According to this theory, audience members approach the media with variable expectations and goals and seek to gratify their needs and wants. Rubin ${ }^{17}$ stated that "communication behavior, including media selection and use, is goal-directed, purposive, and motivated'. Rubin differentiated media orientation as either instrumental or ritualised (or diversionary). An instrumental orientation accommodates selectivity, intentionality and involvement of media consumers. As opposed to instrumental orientation, a ritualised, diversionary orientation refers to the use of a medium such as television in a generalised, time-consuming fashion. According to this definitional scheme, the Internet may be regarded as having more of an instrumental orientation than a diversionary one due to the selectivity and intentionality characteristics associated with banner advertising.

Finally, another theory that could help explain Web choice behaviour is Katz et al.'s process model. ${ }^{18}$ According to this model, the social and psychological origins of needs lead to motivation which leads to the expectation of rewards which causes a person to select sources which, in turn, will give satisfaction. The social and psychological needs which are shared essentially by all media users are:

- cognitive needs (related to strengthening of information, knowledge and understanding of the environment)

- affective needs (related to strengthening aesthetic, pleasurable and emotional experiences)

- personal integrative needs (related to strengthening credibility, confidence, stability and the status of the individual)

- social integrative needs (related to strengthening contact with family, friends and the world)

- escapist needs (related to escape, tension release and desire for diversion).

\section{Conceptual framework}

Greenwald and Leavitt ${ }^{19}$ studied audience involvement as an attention concept and classified level of audience involvement into pre-attention, focal attention, comprehension and elaboration. According to their model, when a 
Behaviour Cues Level of information processing Key effects

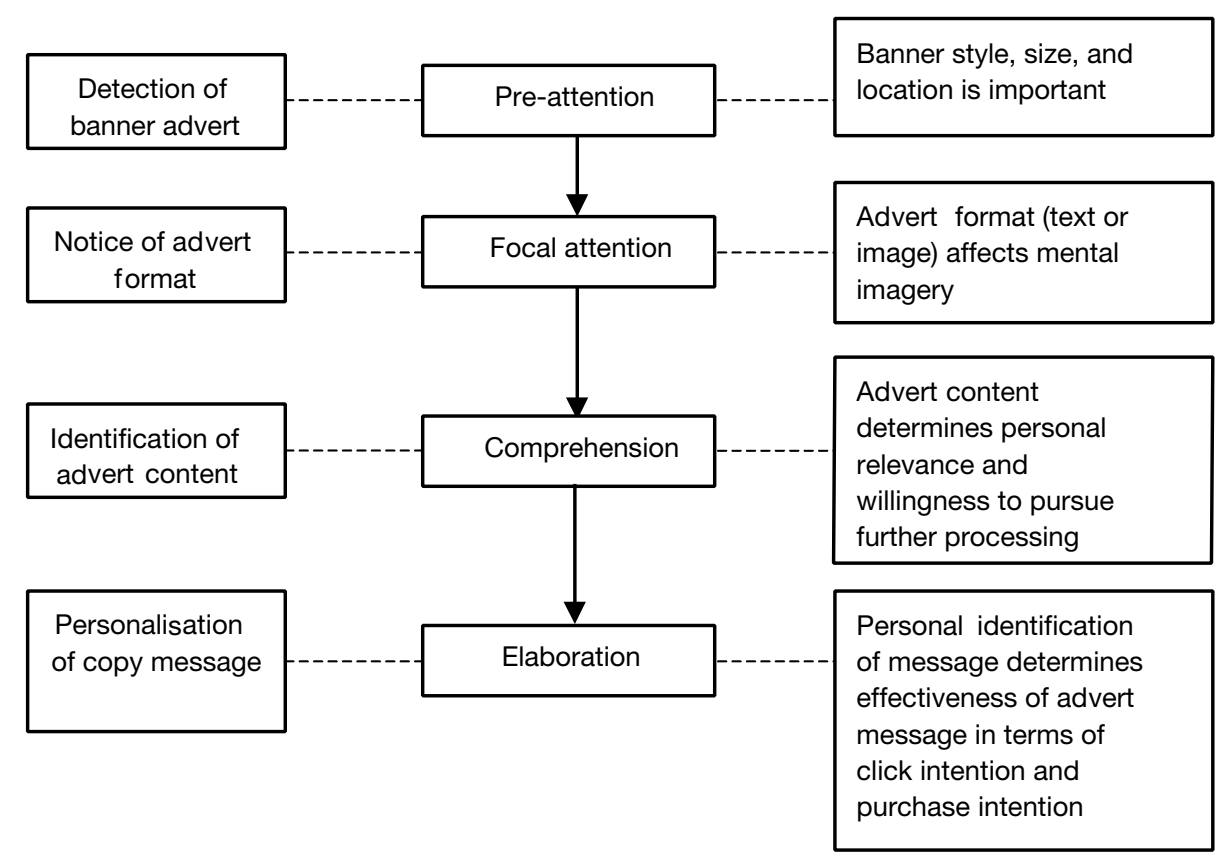

Figure 1 A model of information processing level for banner adverts

message is exposed to an audience, sensory buffering and feature analysis take place at a pre-attention level. At focal attention level, choice of information path and sensory as well as semantic information processing take place and at comprehension level phrase analysis takes place. Finally, at elaboration level, conceptual analysis takes place. In terms of cognitive effects (instant vs persistent), they postulated that at each level of audience involvement, instant advert effects are generated when each process is code-based analysed and when a situation-dependent code is activated. Persistent cognitive effect does not take place at a pre-attention level but at a focal attention level where image is formed. At a comprehension level, a proposition effect takes place, and conceptual effect takes place only at an elaboration level. Finn ${ }^{20}$ advanced the study of Greenwald and Leavitt ${ }^{21}$ one step further to devise a model which prescribed measurement units at each level of information processing based on involvement. This study adapted Finn's conceptual model to explain the basic premises of banner adverts in terms of the level of information processing as depicted in Figure 1.

\section{The effects of advert type on advert effectiveness}

Most of the studies on consumer behaviour concerning the superiority of textual versus pictorial adverts have been approached from two major perspectives. One group of studies focused on distinguishing the effects of advert type (textual vs pictorial) in terms of enhancing consumers' awareness and brand recall. ${ }^{22,23}$ Another group focused on the effects of advert type on consumers' evaluation of product. ${ }^{24,25}$ Viewed collectively, the primary focus of these researchers was on explaining the differential effects of text and image on memory enhancement. ${ }^{26-29}$ One of the 
most predominant findings on the effects of message type is that information conveyed by image is more easily recalled and recognised than textual information. It was argued that image-based information facilitates the use of mental imagery which is recreated in the mind of consumers after stimulus exposure. ${ }^{30-32}$

The banner advert's visual attribute may not, however, always produce positive reaction to the interactive type of advertisement. It was found that depending on the characteristics of the advertisement properties and respondents' orientation (eg visual-ness and verbal-ness dimensions), the interactivity may actually inhibit the process of persuasion; respondents with visual orientation tended to be hampered by the interactive system as opposed to the traditional linear system when the respondents showed decreased purchase intention and spent less time on the advertisements. ${ }^{33}$ Also, Lutz, ${ }^{34}$ who studied advertising effectiveness in terms of memory activation using Yellow Pages, found that of the three types of advertising (interactive pictorial, non-interactive pictorial and text), only the interactive pictorial type produced a significant level of memory activation. Based on the above theoretical and empirical observations, the following hypothesis is set forth:

H1: The banner advert's effectiveness will be significantly affected by advert type.

\section{Effects of consumer involvement on advert effectiveness}

Many previous studies investigated the effects of involvement on advertising effectiveness. When consumers perceive high need for product purchase or the purchase entails high risk, they are likely to be highly involved, whereas when there is little need for purchase, or such purchase does not involve any risk, they are less likely to be involved. Thus, the level of consumer involvement is likely to affect the information processing involving product purchase ${ }^{35}$ and therefore be highly relevant to the study of effectiveness of banner adverts. The role of involvement in advert effectiveness has been extensively studied. For instance, Krugman, ${ }^{36,37}$ who developed the theory of low involvement to explain advert effectiveness, found that involvement exerted significant influence on consumers' response to adverts. He characterised low involvement consumers as possessing the following traits:

- they learn information at random

- they are information gatherers, not seekers

- they represent a passive audience for advertising

- they buy first and evaluate later

- they seek some acceptable level of satisfaction and buy based on only a few attributes.

Another theory which sheds additional light on uninvolved consumers is Sherif's ${ }^{38}$ social judgment theory. This postulates that a highly involved individual who has a definite opinion about an issue would accept very few other positions and would reject a wide number of positions. Conversely, an uninvolved individual would find more positions acceptable or have no opinion about the issue. Rothschild and Houston $^{39}$ extended Sherif's study to predict that highly involved consumers will use more attributes to evaluate fewer brands, while less involved consumers will use fewer attributes to consider more brands. 
The level of influence on memory using different message type (ie text and graphics), had much to do with the level of consumer involvement. In his study, Mowen (see reference 9) reported that text-based information yielded greatest effect when the recipient was highly involved and when the recipient was motivated to process the entire message semantically, whereas graphically oriented information was more effective when the recipient had low involvement.

There is another theoretical approach to explaining the effects of involvement on information processing from the functional attributes of the human brain. According to the split-brain theory, the right-side brain is intended for affective and emotional functions, while the left-side brain is for rational and analytical functions. Generally, in low involvement situations, consumers rely on visual, audio and non-cognitive information. Against this theoretical background, Foote, Cone \& Belding (FCB) advertising agency developed the FCB grid model by incorporating the consumer involvement theory and split-brain theory. Based on the findings of studies on the effects of involvement on the effectiveness of advert type, the following hypotheses are proposed:

H2a: A text-based banner advert is more effective than an image-based advert when consumers are highly involved.

$\mathrm{H} 2 \mathrm{~b}$ : An image-based banner advert is more effective than a text-based advert when consumers are less involved.

Petty and Caccioppo ${ }^{40}$ attempted to explain the effects of involvement through the elaboration likelihood model, which postulated the divergent information processing path (central vs peripheral) contingent upon consumers' level of motivation and information-processing ability. According to the theory, message recipients take a central processing route when they are high in cognitive elaboration (eg when they are involved with the product-related message based on past experience or knowledge), but they take a peripheral route when they are less involved with the message by taking cues from non-product related stimuli such as advert model, background music or graphics. A similar finding was reported by Mitchell ${ }^{41}$ who postulated that in situations of low involvement, level of attention to stimulus is low and hence the attention is directed to non-message elements (eg headline, logo, illustration) rather than message contents, whereas in the highly-involved situation, greater attention is primarily directed towards information about product attributes. Also, Finn $^{42}$ reported that once attention is given to an advert, consumers either try to interpret its meaning according to their goals or they become interested in secondary elements (eg headline, logo, illustration). Also, according to Krugman's $^{43}$ passive learning theory, when consumers are passive and non-interested in the advert, no evaluation of the advert takes place and therefore advertisers should focus on elements of the advert which are less informative about products. Since this study purports to discover the effects of banner adverts in terms of their content (ie information oriented vs prize oriented), the following hypothesis is proposed:

H3a: A product information oriented advert is more effective than a prize oriented advert when consumers are highly involved in the advert.

H3b: A prize oriented advert is more effective than a product information oriented advert when consumers have low involvement in the advert. 


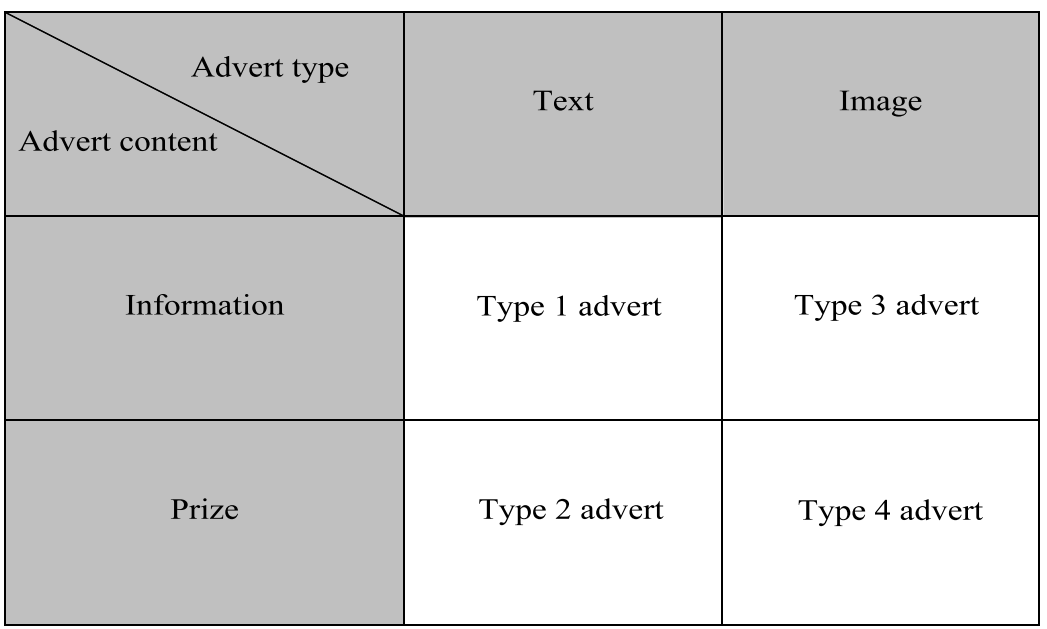

Figure 2 Research design for advert type manipulation

\section{RESEARCH METHODS}

In order to test whether attitudinal responses to advert exposure are associated with effectiveness of the different types of banner adverts, two different properties of advert, 'advert content' and 'advert type', were employed as a basis of advert selection. The 'advert content' refers to the primary content intended by advertisers for consumers' exposure to an advert. To incorporate this attribute into the research design for testing hypotheses two types of advert were adopted which were primarily designed to provide either product information or prize information. Here, the term 'prize' refers to a monetary incentive provided as a compensation for participating in a special promotion initiated by the advertiser. On the other hand, advert type refers to the basic format in which the advert is executed, either textually based or pictorially based.

\section{Advert type classification and questionnaire}

In order to incorporate the above four different conditions into the research design, four different types of adverts were employed for this study. A type 1 advert is a banner advert which is textual and intended for information provision. A type 2 advert is textual and intended for prize provision. A type 3 advert is pictorial and intended for information provision. And a type 4 advert is pictorial and intended for prize provision. The research design with the intention of classifying the four advert type conditions is shown in Figure 2.

The adverts employed for this study were selected from adverts previously executed on the Internet which were deemed by the author as best satisfying the selection criteria set out above. The four adverts were selected from a well-known Korean website where they were actually in use during the same period of time. This method was expected to minimise time or place-based memory contamination which is likely to result when a user is exposed to adverts on different websites and at different times.

The type 1 advert was a banner advert for a life insurance product, the type 2 advert was for an e-shopping mall, the type 3 advert was for fast food (Ramen) and the type 4 one was 
for an automobile tyre. It was believed that these four adverts would provide a better sense of reality than adverts created by a researcher with fixed brand identifications. In order to prevent biased ratings stemming from respondents' affinity with brands used in the study, questions were phrased in terms of 'This type of advert...'. The questionnaire scale was based on a seven-point Likert scale. The actual adverts selected for the study are shown in the Appendix with translations of the copy message.

A questionnaire survey was conducted using a person-to-person interview method - this method was considered more controllable than one using an online survey. This self-reported method may not be as strong as an experimental simulation approach in terms of external validity, but it was deemed more suitable for the intended research objectives, since it can tease out the elements of banner adverts that directly influence subjects' preferential ratings for variations of banner adverts with regard to advert type and advert content. The sample was confined to people living in metropolitan areas of Seoul. Since this study focuses on user-based evaluation of banner adverts, it was deemed appropriate to select the sample from those who have access to the Internet and those who currently use it. Therefore, only those who use the Internet at least one hour per week were selected as a sample. A total of 125 qualified respondents were contacted and of those 114 returned questionnaires. After discarding 14 questionnaires that were unusable, the remaining 100 questionnaires were used for data analysis. Although the final sample size was not large, it was considered appropriate for an experimental database designed to verify the hypothetical directions with adequate statistical robustness.

\section{RESEARCH FINDINGS AND DISCUSSIONS}

\section{Motives for using banner adverts}

In order to find the motives for using banner adverts, 25 question were asked on a seven-point Likert scale. Factor analysis was conducted to learn the respondents' motives for using banner adverts. When the factor analysis was performed with no conditions specified, seven factors were extracted with one factor containing only one item. For this reason, subsequent analyses were conducted with a condition that a factor should contain more than one item. As a result, six factors were chosen which satisfied eigenvalue being greater than one. The result of factor analysis using varimax rotation is shown in Table 1.

The results showed that respondents wanted to use banner adverts for the following six reasons. Most importantly, they used banner adverts to 'maintain social relationships' (34.5 per cent). Secondly, they wanted to 'rest and pass time' (11.9 per cent). Thirdly, they wanted to 'satisfy their curiosity' (7.0 per cent). Fourthly, they wanted to use the banner advert for 'practical reasons' (5.5 per cent). Fifthly, they were motivated by 'two-way communication' (5.0 per cent) function served by the Internet. Finally, they used it out of 'interest in product' (4.5 per cent). Drawing from research on media orientation introduced earlier, the motives for using banner adverts may be regarded as taking on more of an instrumental (eg practical reason, interest in products and satisfy curiosity) orientation than a diversionary orientation (eg rest and pass time). Also, in terms of the process model's social and psychological needs, the motives for using banner adverts addressed cognitive needs (eg practical 
Table 1: Result of factor analyses on the motives for using banner adverts

\begin{tabular}{|c|c|c|c|c|c|c|}
\hline Component Variables & $\mathbf{F 1}$ & $\mathbf{F 2}$ & F3 & F4 & F5 & F6 \\
\hline \multicolumn{7}{|l|}{ Factor 1: Maintain social relationships } \\
\hline I think I am ahead of others & 0.765 & 0.176 & 0.114 & -0.024 & 0.376 & 0.178 \\
\hline By advice from others & 0.714 & 0.228 & 0.060 & 0.336 & 0.002 & 0.031 \\
\hline By habitual force & 0.682 & 0.134 & 0.283 & 0.057 & 0.014 & 0.136 \\
\hline To pass time & 0.669 & 0.391 & 0.161 & -0.001 & 0.092 & -0.202 \\
\hline Since others watch me & 0.625 & 0.515 & 0.117 & 0.084 & 0.251 & -0.016 \\
\hline To diversify my experience & 0.621 & 0.072 & 0.456 & -0.029 & 0.156 & 0.236 \\
\hline To talk about it with others & 0.562 & 0.423 & 0.093 & 0.068 & -0.244 & 0.370 \\
\hline $\begin{array}{l}\text { It is more novel than other media adverts } \\
\text { Factor 2: Rest and pass time }\end{array}$ & & 0.410 \\
\hline I can get away from daily doings & 0.331 & 0.785 & 0.140 & -0.021 & 0.105 & -0.050 \\
\hline I lose interest in websites & 0.202 & 0.737 & 0.335 & 0.000 & 0.221 & 0.054 \\
\hline & \multicolumn{5}{|c|}{ Factor 3: Satisfy curiosity } & 0.053 \\
\hline Since advert is there & -0.026 & 0.198 & 0.766 & -0.066 & 0.167 & -0.025 \\
\hline It is visually interesting & 0.359 & 0.109 & 0.736 & 0.051 & 0.116 & 0.124 \\
\hline Just for fun & 0.283 & 0.392 & 0.687 & 0.086 & 0.033 & 0.076 \\
\hline $\begin{array}{l}\text { Curious for new kind of advert } \\
\text { Factor 4: Practical reason }\end{array}$ & 0.264 & 0.005 & 0.550 & 0.339 & 0.089 & 0.161 \\
\hline To get information about product & -0.090 & -0.080 & 0.183 & 0.789 & 0.046 & 0.155 \\
\hline To purchase product and service & 0.156 & 0.415 & -0.176 & 0.739 & 0.077 & -0.001 \\
\hline Since online purchase is possible & 0.442 & -0.053 & -0.090 & 0.534 & 0.317 & -0.089 \\
\hline $\begin{array}{l}\text { To get information about foreign goods } \\
\text { Factor 5: Two-way communication }\end{array}$ & \multicolumn{5}{|c|}{ Factor 5: Two-way communication } & 0.408 \\
\hline I can see advert whenever I want & 0.021 & 0.029 & 0.085 & 0.201 & 0.722 & 0.043 \\
\hline It is more interactive than other media & 0.389 & 0.124 & 0.215 & 0.027 & 0.678 & 0.159 \\
\hline $\begin{array}{l}\text { To see advert customised for me } \\
\text { Factor } 6: \text { Interest in products }\end{array}$ & -0.173 & 0.376 & 0.098 & 0.246 & 0.429 & 0.393 \\
\hline When the advert is for my favourite product & 0.082 & -0.044 & 0.012 & 0.089 & 0.079 & 0.875 \\
\hline Want to know about specific product & 0.165 & -0.258 & 0.208 & 0.493 & 0.126 & 0.512 \\
\hline To get diversity in information source & 0.220 & 0.165 & 0.217 & 0.055 & 0.483 & 0.493 \\
\hline Eigenvalue & 8.61 & 2.97 & 1.74 & 1.37 & 1.24 & 1.11 \\
\hline Variance explained (\%) & 34.5 & 11.9 & 7.00 & 5.50 & 5.00 & 4.50 \\
\hline Cumulative percent & 34.5 & 46.4 & 53.4 & 58.9 & 63.8 & 68.3 \\
\hline Cronbach alpha & 0.87 & 0.85 & 0.79 & 0.80 & 0.83 & 0.74 \\
\hline
\end{tabular}

reason and interest in products), personal integrative needs (eg satisfy curiosity), social integrative needs (eg maintain social relationship and two-way communication) and escapist needs (eg rest and pass time).

As the purpose of this study was to determine the effectiveness of banner adverts measured by consumers'

perceived preference towards a particular type of banner advert, questionnaire items were composed of the following eight items which describe the respondents' subjective opinions on the banner adverts:

- amount of interest drawn by the advert
- ease of comprehension of the advert message

— credibility

— liking

- recall of the advert

- level of click inducement

- product purchase likelihood

- word-of-mouth experience.

Table 2 shows the result of respondents' responses to advert exposure to four different advert types.

According to the summed ratings for each type of advert, the information oriented advert with pictorial type (type 3) was found to produce the most positive response, followed by the pictorial/prize advert (type 4), the 
Table 2: Result of advert exposure for four different types of banner advert

\begin{tabular}{llccc}
\hline Question Items & $\begin{array}{l}\text { [Type 1] } \\
\text { Information/ } \\
\text { Text }\end{array}$ & $\begin{array}{l}\text { [Type 2] } \\
\text { Prize/ } \\
\text { Text }\end{array}$ & $\begin{array}{l}\text { [Type 3] } \\
\text { Information/ } \\
\text { Image }\end{array}$ & $\begin{array}{l}\text { [Type 4] } \\
\text { Prize/ } \\
\text { Image }\end{array}$ \\
\hline This type of advert interests me & 3.11 & 4.27 & 5.15 & 5.08 \\
The message of this type of advert is easy to & 3.65 & 3.97 & 5.30 & 4.68 \\
understand & 3.14 & 3.20 & 3.99 & 3.63 \\
This type of advert is credible & 2.70 & 3.54 & 4.77 & 3.97 \\
This type of advert is likable & 2.93 & 3.67 & 4.51 & 3.91 \\
This type of advert is memorable & 2.52 & 3.48 & 4.21 & 4.01 \\
This type of advert inclines me to click & 2.47 & 3.14 & 3.75 & 3.41 \\
This type of advert makes me likely to purchase & 2.40 & 3.20 & 3.66 & 3.34 \\
I told others about info from this type of advert & & & 35.37 & 32.03 \\
Total & 22.92 & 28.47 & 37 \\
\hline
\end{tabular}

Table 3: $t$-test results on ad ratings for four banner advert types

\begin{tabular}{lcccc}
\hline Question Items & $\begin{array}{l}t \text {-test } \\
\text { [Type I] } \\
\text { Textual }\end{array}$ & $\begin{array}{l}\text { [Type II] } \\
\text { Pictorial }\end{array}$ & $\begin{array}{l}\boldsymbol{t} \text {-test } \\
\text { [Type III] } \\
\text { Information }\end{array}$ & $\begin{array}{c}\text { [Type IV] } \\
\text { Prize }\end{array}$ \\
\hline $\begin{array}{l}\text { This type of advert interests me } \\
\text { The message of this type of advert is easy to }\end{array}$ & 3.69 & $5.12^{\star \star \star}$ & 4.13 & $4.68^{\star \star *}$ \\
understand & 3.86 & $5.01^{\star \star \star}$ & 4.49 & 4.33 \\
This type of advert is credible & 3.17 & $3.81^{\star \star \star}$ & 3.57 & 3.42 \\
This type of advert is likable & 3.12 & $4.37^{\star \star \star}$ & 3.74 & 3.76 \\
This type of advert memorable & 3.3 & $4.21^{\star \star \star}$ & 3.72 & 3.79 \\
This type of advert inclines me to click & 3.0 & $4.11^{\star \star \star}$ & 3.37 & $3.75^{\star \star}$ \\
This type of advert makes me likely to purchase & 2.81 & $3.58^{\star \star \star}$ & 3.11 & 3.28 \\
I told others about info from this type of advert & 2.80 & $3.50^{\star \star \star}$ & 3.03 & $3.27^{\star \star}$ \\
Total & 25.75 & $33.70^{\star \star \star}$ & 29.15 & $30.25^{\star}$ \\
\hline
\end{tabular}

${ }^{*} p<0.10 \quad{ }^{\star \star} p<0.05 \quad{ }^{\star * \star} p<0.001$

textual/prize advert (type 2) and the textual/information advert (type 1).

Next, in order to investigate further the differences between the adverts in terms of two advert characteristics (ie textual vs pictorial and information vs prize), the four types of advert were rearranged so that textually oriented adverts (advert types 1 and 2) were regrouped as type I and pictorially oriented adverts (types 3 and 4) were regrouped as type II by taking average scores of the two. In the same manner, information intended adverts (types 1 and 3) were regrouped as type III, while prize intended adverts (types 2 and 4) were regrouped as type IV. Then, for the purpose of verifying the difference between advert types based on the two characteristics (ie advert type and advert content), $t$-test was performed on each of the two advert groups (type I vs type II and type III vs the type IV). The result of $t$-tests is presented in Table 3 .

As shown in Table 3 , in all eight items, pictorial adverts were rated as significantly superior to textual adverts. Information oriented adverts did not, however, show such significant differences from prize oriented adverts as there were between pictorial adverts and textual adverts. Prize oriented adverts scored slightly better than information adverts with statistical significance at 0.10 level. Looking at individual items, the prize advert was perceived as significantly better than the information advert in drawing Internet users' interest and in 
Table 4: Attitudes towards four different advert types based on high/low advert involvement

\begin{tabular}{lllll}
\hline & $\begin{array}{l}\text { Text-oriented } \\
\text { Information }\end{array}$ & Prize & $\begin{array}{l}\text { Image-oriented } \\
\text { Information }\end{array}$ & Prize \\
\hline High advert involvement & 3.01 & 4.16 & 4.75 & 4.37 \\
Low advert involvement & $(1.17)$ & $(1.08)$ & $(0.84)$ & $(1.17)$ \\
& 2.48 & 2.63 & 3.83 & 3.42 \\
Total & $(0.88)$ & $(1.09)$ & $(0.97)$ & $(1.18)$ \\
& 2.86 & 3.55 & 4.42 & 4.00 \\
t-test (high vs. low advert & $(1.10)$ & $(1.24)$ & $(1.07)$ & $(1.23)$ \\
involvement) & $\mathrm{F}=3.379$ & $\mathrm{~F}=0.165$ & $\mathrm{~F}=0.926$ & $\mathrm{~F}=0.345$ \\
& Sig(2-tailed) & Sig(2-tailed) & Sig(2-tailed) & Sig(2-tailed) \\
& $=0.041$ & $=0.000$ & $=0.000$ & $=0.001$ \\
\hline
\end{tabular}

*Parenthesised numbers indicate standard deviation

inducing them to click on the advert and in getting them to talk about information from the advert.

In summary, Internet banner adverts were found to be better suited to the pictorial type than the textual one. Also, it was found that prize is a more salient motive for using banner adverts than information is. Thus $\mathrm{H} 1$, which predicted that advert effectiveness is dependent on advert type, is accepted.

\section{The effects of advert involvement}

Next, the effect of advert involvement on the preference of adverts with textual/image presentation type and adverts of information/prize orientation was examined. In order to measure the level of involvement, three question items, 'I have an interest in Internet banner adverts', 'I think that banner adverts are an important source of product information' and 'I tend to rely on banner adverts for product purchase', were used as a measure of involvement. The responses to these questions were averaged and recoded to distinguish the high and low levels of advert involvement. For this purpose, those who answered 'average' were deleted from the data set which resulted in 30 respondents with low involvement and 43 with high involvement. Table 4 shows how favourably the four types of advert were perceived at different levels of advert involvement. The ratings used for the measure of attitude were taken from the average of eight question items which were previously used to measure the level of perceived preference toward Internet banner adverts.

The result in Table 4 indicates that advert involvement had a consistently salient effect on perceived preference of banner adverts in all four different types at 0.05 significance level. That is, respondents with high advert involvement showed higher preference for all four types of banner adverts. But to see how advert involvement interacts with advert type, separate paired sample $t$-tests were performed on advert effectiveness for high and low advert involvements as shown in Table 5 .

As shown in the table, the result of paired comparisons showing the effects of advert type revealed interesting results. It was found that for highly involved consumers, image advert made a significant difference in advert effectiveness only when it was intended for product information. Specifically, an image advert was superior to a text-based advert for an information oriented advert but, for the prize intended advert, image was not significantly better than text. Another important finding is that for low involvement consumers, advert type (ie image) made a consistently significant 
Table 5: Results of paired sample $t$-tests on the type of banner adverts

\begin{tabular}{llllll}
\hline & Comparison & \multicolumn{2}{l}{ High advert involvement } & \multicolumn{2}{l}{ Low advert involvement } \\
Mean & Sig. & Mean & Sig. \\
\hline Pair 1 & $\begin{array}{l}\text { Type 1 advert (info/text) - } \\
\text { Type 3 advert (info/image) }\end{array}$ & $-1.738^{\star \star \star}$ & 0.000 & $-1.345^{\star \star \star}$ & 0.000 \\
Pair 2 & $\begin{array}{l}\text { Type 2 advert (prize/text) - } \\
\text { Type 4 advert (prize/image) }\end{array}$ & -0.209 & 0.281 & $-0.795^{\star \star \star}$ & 0.000 \\
\hline
\end{tabular}

${ }^{*} p<0.10{ }^{* *} p<0.05{ }^{* \star *} p<0.001$

Table 6: Results of paired sample $t$-tests on content of banner adverts

\begin{tabular}{llllll}
\hline Pair & Comparison & \multicolumn{2}{c}{ High advert involvement } & \multicolumn{2}{l}{ Low advert involvement } \\
Mean & Sig. & Mean & Sig. \\
\hline Pair 1 & $\begin{array}{l}\text { Type 1 advert (text/info) }- \\
\text { Type 2 advert (text/prize) }\end{array}$ & $-1.154^{\star \star *}$ & 0.000 & -0.145 & 0.401 \\
Pair 2 & $\begin{array}{l}\text { Type 3 advert (image/info) } \\
\text { Type 4 advert (image/prize) }\end{array}$ & $0.375^{\star *}$ & 0.024 & $0.404^{\star *}$ & 0.035 \\
\hline
\end{tabular}

${ }^{*} p<0.10{ }^{* *} p<0.05{ }^{* * *} p<0.001$

difference in advert effectiveness

regardless of the advert content. This fact explicitly suggests that an image oriented advert is more effective than a text oriented advert for lower involvement consumers than for higher involvement consumers, which was hypothesised by $\mathrm{H} 2 \mathrm{~b}$. Therefore, H2b is accepted. On the other hand, the finding also suggests that a text oriented advert is not more effective than an image oriented advert for highly involved consumers. Therefore $\mathrm{H} 2 \mathrm{a}$ which hypothesised the superiority of a text advert in a high involvement situation is not accepted. As another means of verifying the observation on the superiority of advert type, the effects of advert content were neutralised by averaging two scores (ie information and prize) to find a median point. This measure produced, for the high involvement situation, 3.58 and 4.56 for text advert and image advert respectively. In the low involvement situation, scores were 2.55 and 3.62, respectively.

Therefore, the conclusion can be drawn that advert type was more contingent in its effectiveness on advert content for low involvement consumers than for high involvement consumers. The interface between advert type and advert content in terms of advert effectiveness (measured by preference) is depicted in Figures 3 and 4.

Next, in order to determine the role of advert purpose on advert effectiveness for both high and low involvement, Table 6, showing paired comparisons based on advert content, was prepared.

The table provides important information regarding the effectiveness of advert content. It was found that for both high and low involvement consumers, the advert content showed mixed results in effectiveness contingent upon the advert type. For instance, for highly involved consumers, an information-based advert was superior to a prize-based one when it was presented in image, while a prize advert was superior to an information advert when it was in text. This mixed effectiveness pattern was also detected in the low involvement consumers but with less intensity. For example, for low involvement consumers, an information advert was superior to a prize advert when the 


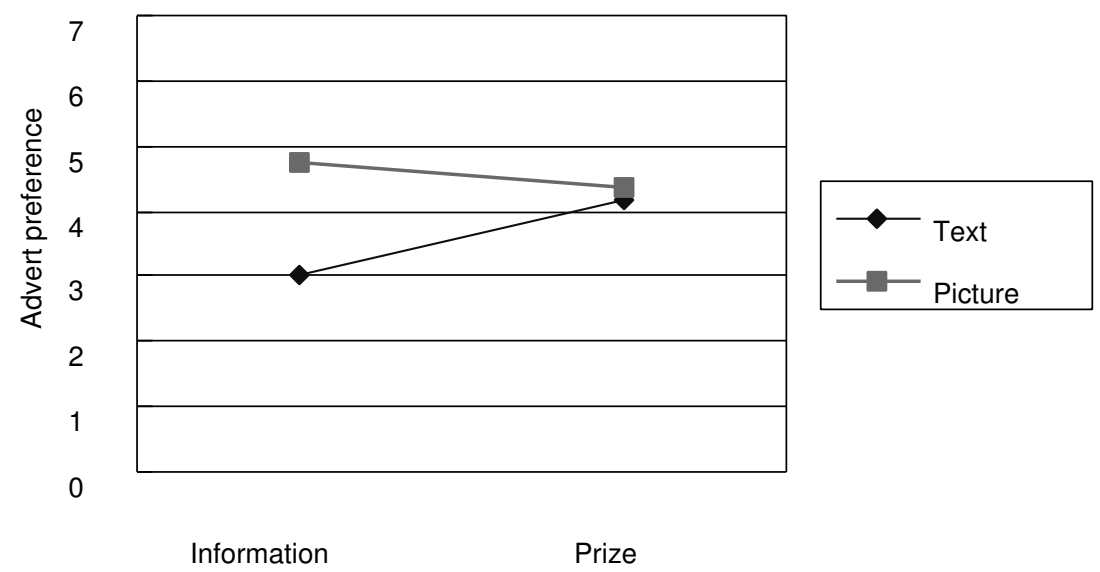

Figure 3 Advert preference for advert type for high involvement consumers

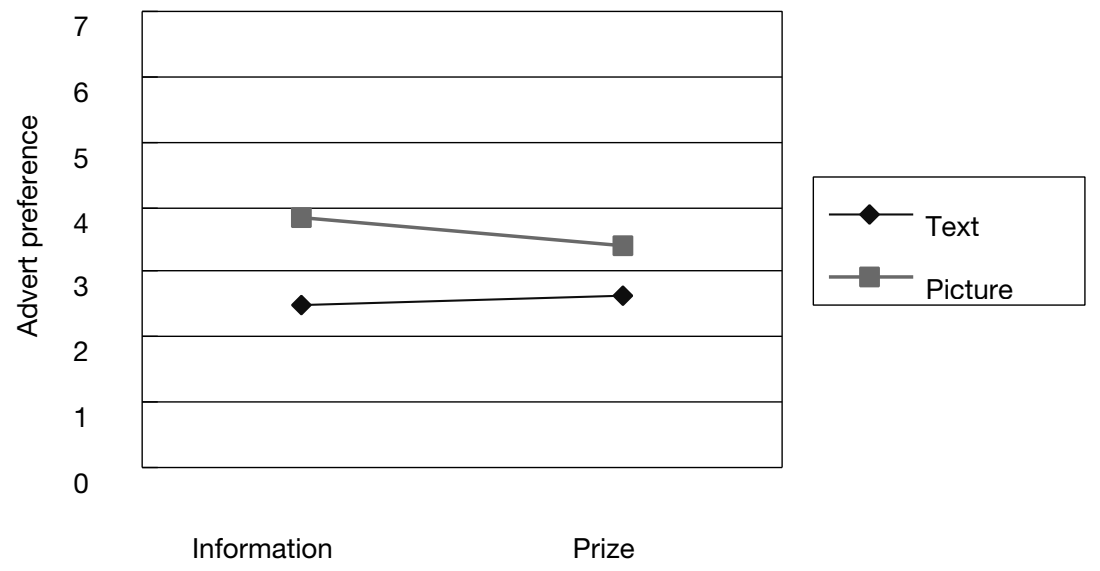

Figure 4 Advert preference for advert type for low involvement consumers

advert was in pictorial type, and an information advert was not significantly more effective than a prize advert when the advert was in textual type. From these findings, it can be concluded that advert content is more format-dependent in effectiveness for highly involved consumers than for low involvement consumers.

Since it was difficult to conclude the relative superiority of advert content in both high and low involvement situations due to the mixed effectiveness of advert content, the effects of advert type were neutralised by averaging the scores (ie text and image) to find a median point. This resulted in, for the high involvement situation, 3.33 and 4.56 for information advert and prize advert, respectively. For the low involvement situation, the scores were 3.15 and 3.02 respectively. From these figures, it can be concluded that the prize-intended advert is more effective than the information intended advert for highly involved consumers, while the information advert is slightly more effective than the prize advert for low involvement consumers. Therefore, H3a and $\mathrm{H} 3 \mathrm{~b}$ which predicted the superiority of text in high involvement and superiority of image in low involvement were not accepted. The interface between advert content and advert type 


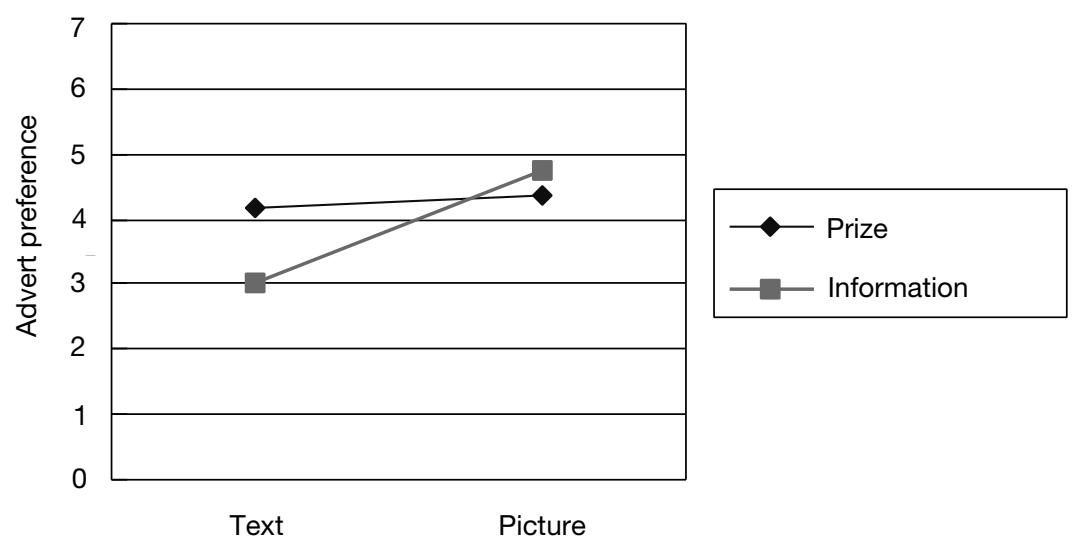

Figure 5 Advert preference for advert content for high involvement consumers

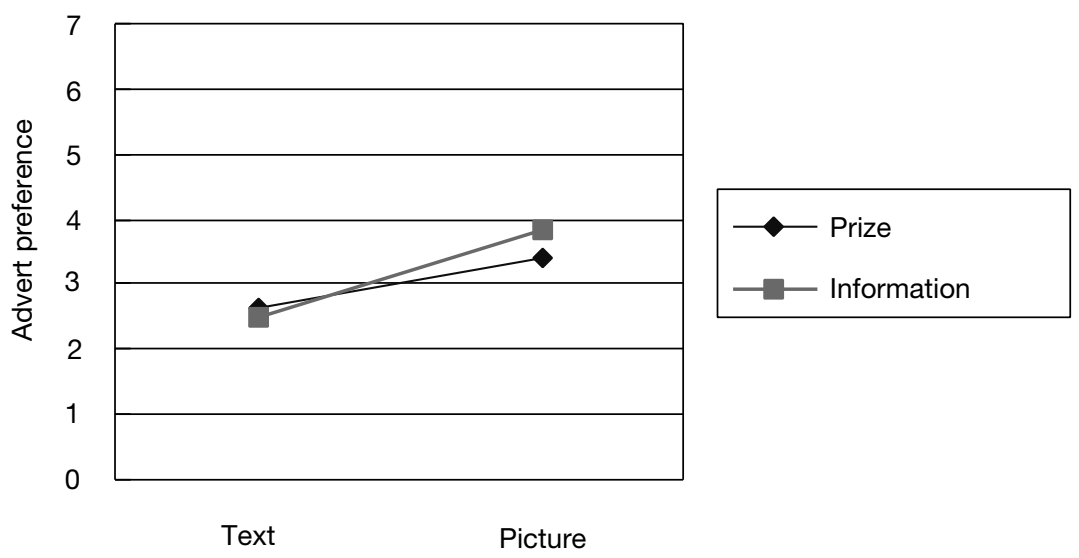

Figure 6 Advert preference for advert content for low involvement consumers

in terms of advert preference is depicted in Figures 5 and 6.

In summary, the level of advert involvement had a significant distinguishing impact on all four types of adverts, resulting in higher advert preference for both advert type and advert content. Both high and low involvement consumers were more positively responsive to an image-based advert than a text-based advert. However, highly involved consumers were significantly more responsive to a prize advert than to an information advert whereas low involvement consumers were slightly more responsive to an information advert.

\section{CONCLUSIONS AND IMPLICATIONS}

The primary objectives of this study were, using empirical data from Internet users in Korea, to discover the major motives for consumers' use of Internet (banner) adverts, and to determine the sources of effectiveness of banner adverts in terms of advert type (text vs image) and advert content (information vs prize) by incorporating theories on the role of consumers' level of involvement on advert effectiveness.

The results showed that respondents wanted to use banner adverts for 'maintaining social relationships,' 'rest and pass time,' 'curiosity,' 'practical reasons,' 
'two-way communication' and for 'interest in product'. It was concluded that the motives for using banner adverts were more of an instrumental nature than a diversionary one. Also, drawing on terms used for the process model's social and psychological needs, the motives for using banner adverts addressed cognitive needs, personal integrative needs, social integrative needs and escapist needs. This finding is important since it shows that the Internet plays an important role in meeting consumers' social, communicative and instrumental needs. This finding should be of interest to media planners who want to develop an effective media mix where the Internet can play an integrative role as well as a complementary one with respect to established media.

Using two properties of banner adverts (advert type and advert content), this study devised four different types of banner adverts to assess their effectiveness as measured by consumers' preferences towards adverts. The results showed that image was significantly more effective than text for Internet banner adverts. It was also found that prize is a more salient motive for the use of banner adverts than information in drawing Internet users' interest and inducing clickthrough behaviour and in producing word-of-mouth effect. It was also found that the level of advert involvement had a significant impact on the effectiveness of all four types of adverts, creating higher advert preference for advert type and advert content when consumers were highly involved. Both high and low involvement consumers were more positively responsive to image adverts than to text adverts. Highly-involved consumers were, however, more positively responsive to prize adverts than to information adverts, whereas low involvement consumers were slightly more positively responsive to information adverts. What is important from this conclusion is that marketers need to get the audience highly involved in the banner adverts. In order to induce a favourable attitude towards a banner advert, they need to understand what affects an audience's interest and attitude towards banner adverts. To this end, marketers need to target different groups of people with different preferences for advert properties. For example, marketers may want to take advantage of information from predefined consumer groups based on data on their visit frequency, clickthrough rates and purchase record. This kind of information will give marketers a good idea about their level of involvement and preference towards targeted product categories. Armed with this knowledge, marketers can then proceed to differentiate advert properties by strategically varying emphasis on different message types and message contents depending on the level of consumer involvement.

A few words of caution are necessary in applying what was found in this study in the real world. First, as this study relied on a controlled-Internet environment (based on a survey instrument), the effectiveness of banner adverts may not exactly simulate the real situation. This set-up may, therefore, run the risk of 'sensitising' respondents to the effects of banner adverts beyond their normal scope of cognitive activity. To reduce this problem, future studies need to attempt an 'experimental simulation' approach where the natural integrity of the online advert-exposure environment is kept intact. Secondly, since real adverts for authentic products were employed, bias-free attitude formation may be difficult due to respondents' implicit brand preference. To rectify this potential problem, a more refined research design could be configured, perhaps by blinding the brand identity. But the value of doing 
this should be determined in a future study. Finally, future studies need to adopt more diverse stimulus in addition to advert type and advert content. Since banner adverts are taking multimedia platforms, more sophisticated research design should look at the effects of animation, sound, colour and size/location of the banner. In a related context, a future study might benefit from a cross-cultural study comparing different data sets stemming from different cultural regions, where banner adverts may be conceived differently due to divergent value systems.

\section{Acknowledgments}

The author thanks two anonymous reviewers for their helpful comments. This research was supported by Kyonggi University Research Grant (Ref No. 2002-001).

\section{References}

1 Berthon, P., Pitt, L. F. and Watson, R.T. (1996) 'The World Wide Web as an advertising medium: Toward an understanding of conversion efficiency', Journal of Advertising Research, Vol. 36, pp. 43-54.

2 Dreze, X. and Zufryden, F. (1997) 'Testing web site design and promotional content', Journal of Advertising Research, Vol. 37, pp. 77-91.

3 Clawson, P. (1993) 'Study: Consumers want interactive TV', Electronic Media, 23rd August, pp. 24-25.

4 Kim, J. (1997) 'The variable influence of audience activity on media effects', Communication Research, Vol. 24, No. 2, pp. 107-136.

5 Park, C. H., Kim, Y. J., Kwak, H. W., Lee, J. G., Sung, K. J. and Lee, J. M. (1997) 'Exploratory learning and users' strategy in search of internet information', Annual Conference of Korean Psychology Association.

6 Childers, T. L. and Houston, M. J. (1984) 'Conditions for a picture superiority effect on consumer memory', Journal of Consumer Research, Vol, 11, September, pp. 643-651.

7 Lutz, K. A. and Lutz, R. J. (1976) 'Effects of interactive imagery on learning: Application to advertising', Journal of Applied Psychology, Vol. 62, pp. 493-498.

8 Milgram, A. A. (1967) 'Verbal context versus visual compound in paired-associate learning by children', Journal of Experimental Child Psychology, Vol. 5, pp. 597-603.

9 Mowen, J. C. (1988) 'Beyond consumer decision making', Journal of Consumer Marketing, Vol. 46, Summer, pp. 92-101.

10 Bezjian-Avery, A., Calder, B. and Iacobucci, D. (1998) 'New media interactive advertising vs. traditional advertising', Journal of Advertising Research, July/August, pp. 23-33.

11 Clawson (1993) op. cit.

12 Park et al. (1997) op. cit.

13 Lee, H. W. (1997) 'A study of the economic value of Internet: Focus on Internet advert and cyber marketing', Advertising Studies, Summer, pp. 33-54.

14 Korean Advertisers' Association (1997) 'Survey of Internet and $\mathrm{pc}$ communication users in Korea'.

15 Hunter, C. D. (1996) 'The uses and gratifications of the World Wide Web', manuscript presented at the Depauw University National Undergraduate Honors Conference.

16 Dervin, B. (1989) 'Rethinking communication', Sage Publications, London.

17 Rubin, A. M. (1994) 'Media uses and effects: A uses and gratifications perspective', in Bryant, J. and Zillmann, D. (eds) 'Media effects: Advances in theory and research', Lawrence Erlbaum, Hillsdale, NJ, pp. 417-436.

18 Edelstein, A. S. (1989) 'Communication and culture', Longman Inc, New York.

19 Greenwald, A. G. and Leavitt, C. (1984) 'Audience involvement in advertising: Four levels', Journal of Consumer Research, Vol. 11, No. 1, pp. 581-592.

20 Finn, A. (1988) 'Print advert recognition readership scores: An information processing perspective', Journal of Marketing Research, Vol. 25, May, pp. 168-177.

21 Greenwald and Leavitt (1984) op.cit.

22 Lutz, R. J. (1977) 'An experimental investigation of causal relations among cognitions, affect, and behavioral intentions', Journal of Consumer Research, Vol. 3, March, pp. 197-208.

23 Pavio, A. (1969) 'Mental imagery in associative learning and memory', Psychological Review, Vol. 76, May, pp. 241-263.

24 Kisielius, J. and Sternthal, B. (1984) 'Detecting and explaining vividness effects in attitudinal judgments', Journal of Marketing Research, February, Vol. 3, No. 10, pp. 29-49.

25 Wright, P. and Rip, P. C. (1980) 'Product class advertising effects on first-time buyers' decision strategies'. Journal of Consumer Research, Vol. 7, September, pp. 176-188.

26 Childers and Houston (1984) op. cit.

27 Milgram (1967) op. cit.

28 Mowen (1988) op. cit.

29 Lutz and Lutz (1976) op. cit.

30 Childers and Houston (1984) op. cit.

31 Leong, E. K., Huang, X. and Stanners, P. J. (1998) 'Comparing the effectiveness of the website with traditional media', Journal of Advertising Research, September/October, p. 45-51.

32 Unnava, H. R. and Burnkrant, R. E. (1991) 'An imagery-processing view of the role of pictures in print advertisements', Journal of Marketing Research, Vol. 28, May, pp. 226-231.

33 Bezjian-Avery (1998) op. cit.

34 Lutz (1977) op. cit.

35 Zaichkowsky, J. L. (1985) 'Measuring the involvement construct', Journal of Consumer Research, Vol. 12, December, pp. 341-352. 
36 Krugman, H. E. (1977) 'Memory without recall, exposure with perception', Journal of Advertising Research, Vol. 17, August, pp. 7-12.

37 Krugman, H. E. (1965) 'The impact of television advertising: Learning without involvement', Public Opinion Quarterly, Vol. 29, pp. 349-356.

38 Sherif, S. and Nevergall, R. (1964) 'Attitude and attitude change', Yale University Press, New Haven, $\mathrm{CN}$.

39 Rothschild, M. L. and Houston, M. J. (1977) 'The consumer involvement matrix: Some preliminary

\section{APPENDIX}

\section{Advert Type 2}

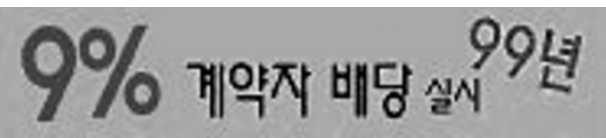

(1)

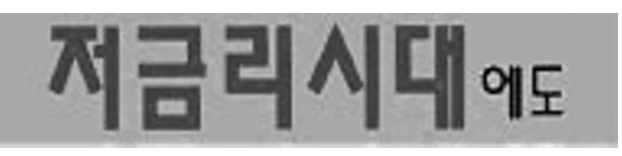

(2)

\section{교보슝명}

(3)

Translation: (1) '9 per cent subscriber dividends given in 1999; (2) Kyobo Insurance is good; (3) even in this Low Interest Rate Age'. findings', in proceedings of the American Marketing Association Educators' Conference, pp. 95-98.

40 Petty, R. E. and Caccioppo, J. T. (1986)

'Communication and persuasion: Central and peripheral routes to attitude change', Springer-Verlag, New York, NY.

41 Mitchell, A. A. (1984) 'Involvement: A potential important mediator of consumer behavior', Advances in Consumer Research, Vol. 6, pp. 191-196.

42 Finn (1988) op. cit.

43 Krugman (1965) op. cit.

\section{Advert Type 2}
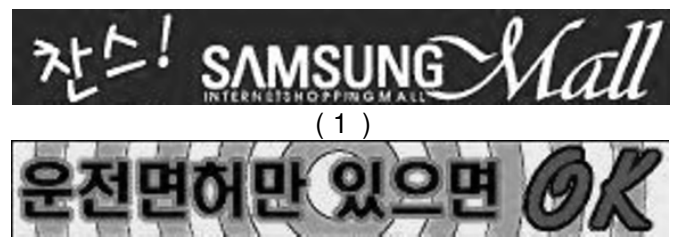

(2)

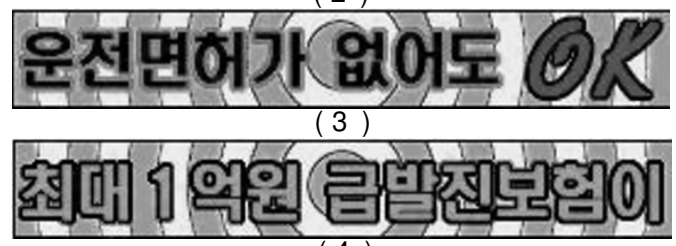

(4)

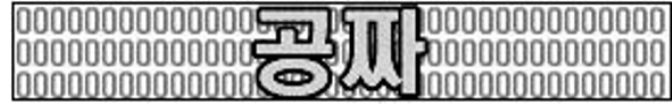

(5)

Translation: (1) Chance! Samsung Mall; (2) It's OK if you only have driver's licence; (3) It's OK even if you don't have driver's licence; (4) Maximum 100m Won sudden car start insurance is (5) FREE.

\section{Advert Type 3}

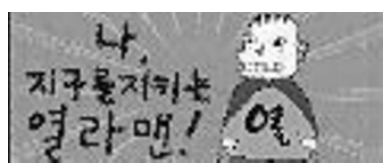

(1)

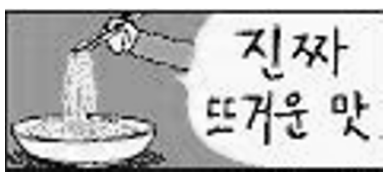

(4)

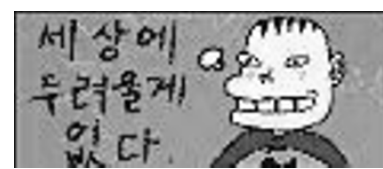

(2)

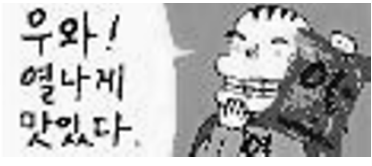

(5)

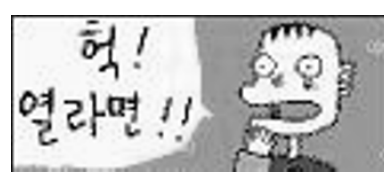

(3)

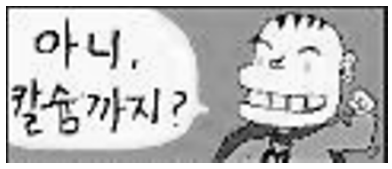

(6)

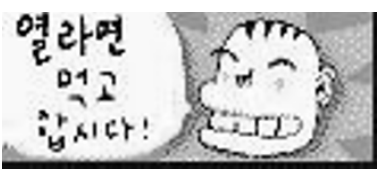

( 7 )

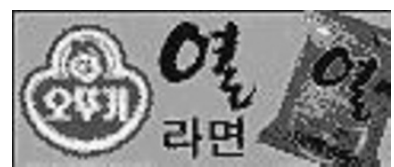

(8)

Translation: (1) I am a defender of earth, Steam Ramen; (2) I am afraid of nothing; (3) Huh! Steam Ramen!!; (4) Really hot taste; (5) Wow! It's steamy tasty; (6) Wow, even Calcium?; (7) Let's do it after Steam Ramen!; (8) Steam Ramen (with its brand logo). 
Advert Type 4

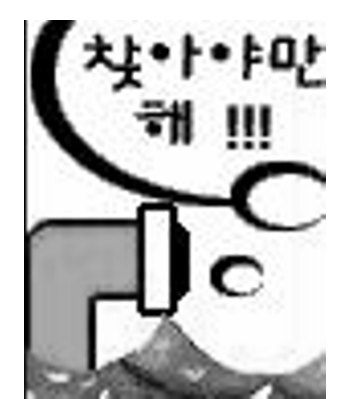

(1)

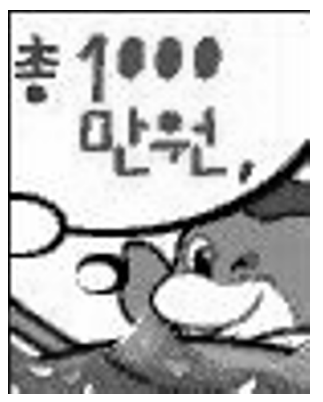

(5)

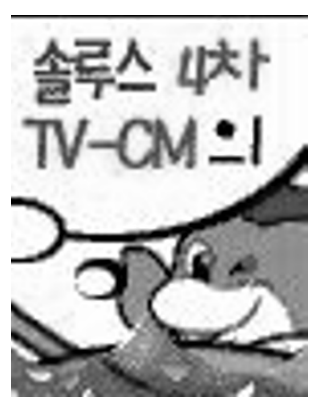

(2)

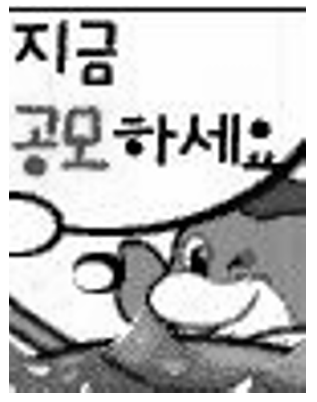

(6)

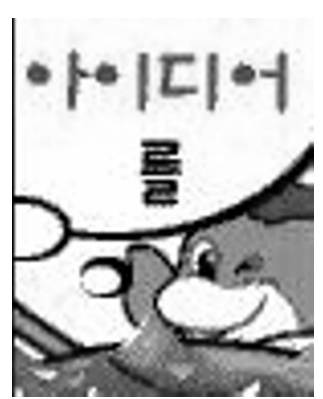

( 3 )

\section{라타에} rons:

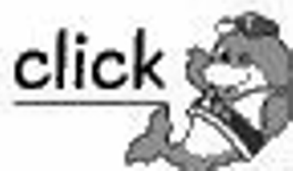

( 7 )

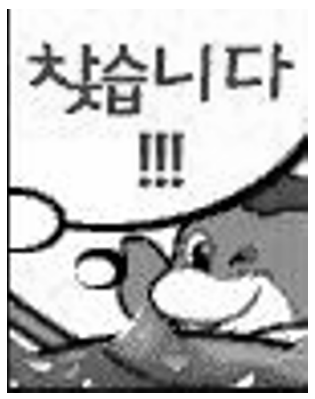

(4)

Translation: (1) I must find it!!!; (2) Soluth 4th TV-Commercial's; (3) Idea; (4) is being searched; (5) for a total of $10 \mathrm{~m}$ Won; (6) Apply for it now; (7) Click (with Keumho Tyre's logo). 